\title{
Development of a staged anaerobic pond for methane recovery from domestic wastewater
}

\author{
P.H. Cruddas ${ }^{1 *}$, E.J. McAdam ${ }^{1}$, N. Asproulis ${ }^{2}$, A. Antoniadis ${ }^{2}$, I. Ansari ${ }^{1}$, D. Best ${ }^{3}$, B. \\ Jefferson ${ }^{1}$, E. Cartmell ${ }^{1}$, G. Collins ${ }^{4}, 5$, E. Porca ${ }^{4}$ M. R. Peña-Varón ${ }^{6}$ \\ 1. Cranfield Water Science Institute, Cranfield University, UK \\ 2. Department of Engineering Physics, Cranfield University, UK \\ 3. Halcrow Group, Elms House, 43 Brook Green, London, UK \\ 4. Microbial Communities Laboratory, School of Natural Sciences, National University \\ Ireland Galway, University Road, Galway, Ireland \\ 5. Infrastructure and Environment, School of Engineering, University of Glasgow, UK \\ 6. Universidad del Valle, Instituto Cinara, Cali, Colombia \\ *Corresponding author
}

\begin{abstract}
Since their inception in larger pond systems, the focus of anaerobic ponds has shifted from solids removal to optimising biogas production and reducing physical footprint to minimise land requirements. In this study, a horizontally baffled (HBAP) and vertically baffled (VBAP) anaerobic pond were compared. Distinct differences in the removal efficiency of COD fractions were observed, with particulate COD removal of $78 \%$ and $32 \%$, and soluble COD removal of $-26 \%$ and $19 \%$ in the HBAP and VBAP, respectively. A staged pond (SAP) was constructed through an HBAP placed upstream of a VBAP, with an additional HBAP used as a control (CAP). The SAP demonstrated superior biogas recovery potential over the control: methane production by the conclusion of the study was 6.09 and $9.04 \mathrm{LCH}_{4} \mathrm{~m}^{-3}$ wastewater treated for the CAP and SAP, respectively. Methanogenic activity in the ponds was higher closer to the outlet, and hydrogenotrophic methanogenesis dominated over acetoclastic pathways.
\end{abstract}

Keywords: Waste stabilisation lagoons, psychrophilic treatment, anaerobic baffled reactors, biogas 


\section{Introduction}

Aspirations around the delivery of more sustainable sewage treatment require consideration of fugitive Green House Gas (GHG) emissions; generation of large quantities of sludge for storage and disposal, and the use of electricity to deliver aerobic treatment environments. In the case of rural sewage works additional aspirations exist with regard to the reduction in sludge tanker visits and use of external supplies of chemicals or energy due to the disproportionate infrastructure costs associated with providing them. Anaerobic ponds (APs) present an exciting potential option in response to such requirements by delivering three key benefits: reduced organic carbon loads onto secondary aerobic treatment processes reduces electrical energy demand (McAdam et al., 2012); low parasitic energy demand and low sludge management requirements (Alexiou and Mara, 2003) provide a small energy and carbon footprint; and retained carbon can be converted to biogas for renewable energy generation (Shilton et al., 2008).

Anaerobic ponds were first developed as a pre-treatment stage in larger pond systems (Pescod, 1996) to reduce particulate loading on downstream facultative and maturation ponds. In such systems, design loading rates were developed through empirical observation and were deliberately conservative to minimise odour nuisance from the uncovered ponds, thereby inhibiting the potential for biogas production (Park and Craggs, 2007). The covering of APs is now recommended for environmental protection (Noyola et al., 2006) and energy capture (Park and Craggs, 2007). The role, 
and focus, of APs is shifting from primary sedimentation to more complete organic breakdown and toward flexibility along treatment flowsheets. Thus, a new design approach is required to focus on optimising the biological processes whilst minimising physical footprint, alongside the traditional requirement of solids removal. The separation of solids retention time (SRT) from hydraulic retention time (HRT) is critical to ensure sufficient retention and degradation time for particulate carbon, whilst contact between the retained biomass and the liquid layer must also be facilitated to target soluble carbon fractions that are an essential step in methane production (Lew et al., 2009).

Traditionally APs have been designed as single-stage unbaffled reactors, rectangular in shape with a recommended length:width ratio of 3:1, and designed for a recommended HRT of 1-3 d, depending on the operating temperature (Mara and Pearson, 2008). However, more recent studies on APs and anaerobic baffled reactors (ABRs) investigated the incorporation of baffles to improve hydrodynamic performance and to increase mixing (Peña et al., 2003; Langenhoff and Stuckey, 2000). Horizontal baffles, which produce a lane system creating 'side to side' flow, move the flow regime closer toward plug-flow conditions (Muttamara and Puetpaiboon, 1997), thereby maximising sedimentation. In contrast, vertical baffles create 'up-and-under' flow, which provides greater biomass contact and has been demonstrated to separate the stages of anaerobic digestion (AD) along the reactor length, with acidogenesis observed in the compartments closest to the inlet and methanogenesis further down the reactor (Barber and Stuckey, 1999). The development of specific microbial communities in each chamber was observed, and this separation, due to preferential 
conditions for differing but complementary communities along the reactor length, has been found to increase acidogenic and methanogenic activity by up to a factor of four compared to unbaffled anaerobic systems (Barber and Stuckey, 1999).

The incorporation of baffles into APs will affect the flow profile through the pond, and quantifying changes in hydrodynamics facilitates greater understanding of pond treatment mechanisms (Peña et al., 2003; Persson and Wittgren, 2003; Abbas et al., 2006; Abbassi et al., 2009). Whilst the hydrodynamic performance of ponds has traditionally been analysed through experimental tracer studies, computational fluid dynamics (CFD) modelling has become an increasingly more powerful and accessible tool for pond designers since its first application for this purpose by Wood et al. (1995). Studies using CFD to investigate pond design have been numerous, and have included pond geometry, inlet and outlet location, and various horizontal baffling configurations (Wood et al., 1995; Persson, 2000; Salter et al., 2000; Vega et al., 2003; Shilton and Mara, 2005). However, most lack validation through comparison with experimental data (Shilton et al., 2008; Alvarado et al., 2012). Additionally, the majority of studies reported has been conducted on facultative or maturation ponds, with a focus on achieving plug-flow conditions (Shilton and Harrison, 2003), whereas the importance of mixing for biomass contact with the liquid layer is being increasingly recognised in APs (Peña et al., 2003). Furthermore, whilst the evolution of CFD models from two to three dimensions has led to increased modelling potential, there are currently no available studies on CFD modelling of vertical baffles in the literature. The use of CFD modelling, if suitably validated with experimental tracer studies, can 
provide insight into intra-pond flow characteristics that is not possible from merely analysing tracer study data (Shilton, 2000).

This paper reports on the development of a staged anaerobic pond (SAP), conceived through initial studies of horizontally- (HBAPs) and vertically-baffled anaerobic ponds (VBAPs), using pilot scale trials and CFD modelling. The aim was to assess the effect of differing baffle orientations in single-stage reactors, and subsequently between a twostage and single-stage AP.

\section{Materials and Methods}

\subsection{Experimental set-up}

Two pilot-scale reactors (the VBAP and HBAP) were constructed of 12-mm-thick uPVC sheeting and sealed with PVC hot welding. The internal dimensions were $1.5 \mathrm{~m} \times 0.5 \mathrm{~m}$ $\times 0.25 \mathrm{~m}$ for the VBAP and $1.5 \mathrm{~m} \times 0.5 \mathrm{~m} \times 0.31 \mathrm{~m}$ for the HBAP, giving hydraulic volumes of $188 \mathrm{~L}$ and $230 \mathrm{~L}$, respectively. A length:width ratio of 3:1 was used in accordance with recommended AP design (Mara and Pearson, 1998). The VBAP contained four baffles located at $\mathrm{L} / 5,2 \mathrm{~L} / 5,3 \mathrm{~L} / 5$ and $4 \mathrm{~L} / 5$, which extended the entire width of the reactor and $80 \%$ of its height. The baffles alternated between sitting on the base of the reactor - thus forcing flow over the baffle - and standing against the lid of the reactor - forcing flow under the baffle (Figure 1). The HBAP contained two baffles, located at $\mathrm{L} / 3$ and $2 \mathrm{~L} / 3$ along the reactor length, which extended the entire height of the reactor and $85 \%$ of the reactor width (Peña et al., 2003). The reactors 
were sealed with gas-tight lids. These two reactors were operated as single stage systems for the first phase of the study.

Consequently, the SAP was created by connecting the two in series, with the HBAP located upstream of the VBAP. A control pond (CAP) was constructed with the same specifications as the original HBAP. Side ports were fitted to the CAP and SAP for sampling from each chamber created by the baffles. The side ports were labelled C1, $\mathrm{C} 2$ and $\mathrm{C} 3$ for the CAP chambers; $\mathrm{H} 1, \mathrm{H} 2$ and $\mathrm{H} 3$ for the chambers in the first (HBAP) stage and V1, V2, V3, V4 and V5 for the chambers in the second (VBAP) stage of the SAP.

All reactors, at the start of both phases, were initially seeded at $7 \%$ of their volume with mesophilic anaerobic sludge from a digester (volatile solids, VS $=36 \mathrm{~g} \mathrm{~L}^{-1}$ ), filled with crude wastewater from the Cranfield University sewage treatment works and then left in batch for one day. The single stage HBAP and VBAP, in the first phase, and CAP in the second stage, were then fed continuously with crude wastewater at a liquid flow rate of $75 \mathrm{~L} \mathrm{~d}^{-1}$. The SAP was operated at a flow rate $150 \mathrm{~L} \mathrm{~d}^{-1}$ to produce the same HRT as the control. For the CFD validation only, an unbaffled pond (UAP) was created by removing the baffles from the HBAP. Tracer studies for CFD validation experiments were conducted in all reactors operating with water only and without seed.

\subsection{Analytical methods}

Influent and effluent were analysed three times a week in duplicate, whilst internal sampling in the SAP trial was conducted once a month. Total suspended solids (TSS), volatile suspended solids (VSS), total COD (tCOD) and soluble COD (SCOD), biochemical 
oxygen demand $\left(\mathrm{BOD}_{5}\right)$ were measured according to standard methods (APHA, 1998). Samples for sCOD were filtered through 1.2- $\mu \mathrm{m}$ glass fibre filters (Whatman, Maidstone, UK). Particulate COD fraction ( $p C O D$ ) was calculated by subtracting sCOD from tCOD. Ambient and liquid temperatures were recorded the time of sampling. Analysis of variance tests were carried out on the effluent data sets from the staged pond trial, with unpaired t-tests used for normally distributed data sets and MannWhitney tests for non-parametric data. Six volatile fatty acids (VFA) were measured using high performance liquid chromatography (HPLC) in a fermentation separation column (Bio-Rad, California, USA). Biogas was captured from the lids of the reactors in gas-tight sampling bags and analysed twice a week for total volume and gas composition. Gas volume was measured using a displacement technique (Mshandete et al., 2005) and composition was determined by gas chromatography with a thermal conductivity detector (CSi 200 Series, Cambridge Scientific Instruments Ltd, Cambridge, UK). Specific methanogenic activity (SMA) assays were done in triplicate using sludge samples taken from each chamber of the CAP and SAP at the conclusion of the study. The SMAs, which were based on the tests of Colleran et al. (1992) and Coates et al. (1996), and followed the procedures of Collins et al. (2003), contained 3-5 g volatile suspended solids (VSS) L'-1. Biomass samples were separately assayed against the direct methanogenic substrates acetate $(30 \mathrm{mM})$ and $\mathrm{H}_{2} / \mathrm{CO}_{2}(80: 20, \mathrm{v} / \mathrm{v})$. Assays without substrate, or with a pressurised $\mathrm{N}_{2} / \mathrm{CO}_{2}$ headspace only, were used respectively as controls for acetoclastic and hydrogenotrophic methanogenic assays. Rates of activity were expressed as $\mathrm{ml} \mathrm{CH}_{4} \mathrm{~g} \mathrm{VSS}^{-1} \mathrm{~d}^{-1}$. 
Tracer studies were performed with Lithium $\left(\mathrm{Li}^{+}\right)$. A LiCl (>99\% reagent grade) solution of $306 \mathrm{~g} \mathrm{~L}^{-1}$ was prepared, and a pulse signal of $4 \mathrm{~mL}$ de-ionised water was introduced to the influent, for a total pulse $\mathrm{Li}^{+}$mass of $200 \mathrm{mg}$. Grab samples were collected in the effluents at regular intervals over a period equivalent to three HRTs. Control samples were taken prior to dosing to analyse for background $\mathrm{Li}^{+}$. Lithium concentrations were determined by atomic emission spectroscopy (Perkin Elmer model AAnalyst 800, using an air-acetylene flame method at $670.80 \mathrm{~nm}$ ) with a minimum detection limit of 0.05 $\mathrm{mg} \mathrm{L}^{-1}$.

\subsection{CFD modelling}

Three-dimension single-phase CFD simulations were performed using the commercial software FLUENT v14.0.0 (ANSYS). Geometries for the four reactor designs were drawn in AutoCAD 2007 (AutoDesk, Inc.) and meshed using ICEM CFD (ANSYS). Meshes contained total elements of $1,535,058$ for the UAP, $2,234,971$ for the HBAP, $2,060,338$ for the VBAP and 3,012,830 for the SAP. The laminar flow model was used as the Reynolds number for all ponds was less than 6 . The fluid in the ponds was assumed to be incompressible and exhibiting Newtonian fluid properties of water with a density of $998.2 \mathrm{~kg} \mathrm{~m}^{-3}$ and a dynamic viscosity of $1.003 \times 10^{-3} \mathrm{~kg} \mathrm{~m}^{-1} \mathrm{~s}^{-1}$. The inflow boundary condition was defined as a mass-flow-inlet with a constant mass flow of $1.3 \times 10^{-3} \mathrm{~kg} \mathrm{~s}^{-1}$ for the single stage reactors and $2.6 \times 10^{-3} \mathrm{~kg} \mathrm{~s}^{-1}$ for the staged reactor. The outflow boundary condition was defined as a pressure-outlet with a gauge pressure of 0 pascal. The tracer RTD analysis was performed by imposing a transient simulation of the tracer 
as a scalar on the velocity and turbulent fields obtained from the flow simulation using the method proposed by Alvarado et al. (2012).

\section{Results}

\subsection{Comparison of the horizontally and vertically baffled ponds}

Removal efficiencies of the two single-staged baffles ponds were markedly different. High and consistent particulate removal in the HBAP contrasted with lower and more variable removal in the VBAP (Figure 2). To illustrate, mean TSS removal efficiency in the HBAP was $80 \pm 9 \%(n=14)$ cf. $35 \pm 15 \%(n=20)$ in the VBAP. This corresponded to mean pCOD removal of $73 \pm 21 \%$ in the HBAP compared to $32 \pm 32 \%$ in the VBAP. By contrast, a mean SCOD removal of $-15 \%$ was recorded in the HBAP whilst positive removal of $21 \%$ was recorded in the VBAP. The removal efficiencies recorded show the HBAP was superior at removing particulate fractions from the wastewater, whilst increasing the soluble COD from influent to effluent, suggesting particulate degradation to soluble products, which were not sufficiently treated within the system. Conversely, the VBAP did remove a fraction of soluble COD, although was inferior to the HBAP in removing the particulate fractions present in the raw influent.

\subsection{Pilot trial of a staged anaerobic pond design}

There were no statistical differences between the removal efficiencies of the CAP and SAP for any of the measured sanitary parameters to a 95\% confidence level (Figure 3). Particulate removal was concentrated at the front of both ponds, with $65 \%$ of total TSS removal observed in the first chamber of the CAP (equal to $33 \%$ of total pond length), and $85 \%$ removal observed in the front chamber of the SAP (equal to $17 \%$ of 
total pond length). Total sludge accumulation in the front chamber of each pond was 15.0 and $20.6 \mathrm{~L}$ for the CAP and SAP respectively (Table 1), comprising $63 \%$ and $39 \%$ of the total sludge volume for each pond, indicating that the settlement of solids is more dependent on the baffle placement than on pond length. Sludge in the second (vertically baffled) stage of the SAP was evenly distributed, with $4.1 \mathrm{~L}$ observed in the first chamber, V1, and 4.0 L observed in the final chamber, V5, suggesting there was little sludge carry-over from the first stage, and the initial seed remained immobilised in the respective chambers.

Negative sCOD removal was observed in both ponds (Figure 3), with mean $-30 \pm 28 \%$ and $-41 \pm 45 \%$ for the CAP and SAP, respectively. No relationship was observed between negative SCOD removal and time in either pond, suggesting rapid initiation of acidogenesis without a start-up trend. The production of SCOD in both ponds can be linked to VFA creation, as negative VFA removal was also observed in both reactors. Acetic acid comprised $45 \%$ of total measured VFA in both reactors (Table 1 ), suggesting a significant amount of acetate was not only generated in the ponds, but was still accumulated and available as substrate throughout both ponds.

\subsection{Biogas production from the staged anaerobic pond pilot trial}

In contrast to VFA formation, start-up of overall biogas methane production was similar in both the CAP and the SAP, with a lag of 45 days before production was observed, and then increasing production until day 80 (Figure 4). Mean production rates recorded for the final two weeks of the study were 6.09 and $9.04 \mathrm{LCH}_{4} \mathrm{~m}^{-3} \mathrm{WWT}$ for the CAP and SAP, respectively. Whilst maxima found in the CAP are comparable to 
the SAP, low values were also measured throughout the study, whilst the SAP produced more consistent measurements (Figure 4). To illustrate, the range of production rates observed over the final two weeks of the study was $22.16 \mathrm{LCH}_{4} \mathrm{~m}^{-}$ ${ }^{3}$ WWT for the CAP $c f .13 .28 \mathrm{LCH}_{4} \mathrm{~m}^{-3} \mathrm{WWT}$ for the SAP.

3.4 Methanogenic activity of sludge samples taken from the staged anaerobic pond pilot trial

Methane formation, measured through SMA assays, showed greater utilisation by the pond sludge samples of hydrogen as a substrate over acetic acid. Mean net SMA $A_{\text {hydrogen }}$ $=604.03 \mathrm{mLCH}_{4} \mathrm{gVSS}^{-1} \mathrm{~d}^{-1} c f . \mathrm{SMA}_{\text {acetate }}=1.04 \mathrm{mLCH}_{4} \mathrm{gVSS}^{-1} \mathrm{~d}^{-1}$ in the CAP, and mean net $\mathrm{SMA}_{\text {hydrogen }}=1,460.89 \mathrm{mLCH}_{4} \mathrm{gVSS}^{-1} \mathrm{~d}^{-1} c f . \mathrm{SMA}_{\text {acetate }}=6.28 \mathrm{mLCH}_{4} \mathrm{~g} \mathrm{VSS}^{-1} \mathrm{~d}^{-1}$ in the SAP, indicate higher hydrogenotrophic than acetoclastic methanogenic activity. The SMA essays do not discount the possibility of syntrophic acetate oxidation by bacteria, which could fuel hydrogenotrophic methangenesis; equally, the SMA data do not discount the possibility of homoacetogenic oxidation of hydrogen leading to acetate production. However, the combined observations of VFA measurements and SMA testing indicate that acetate accumulated in the system and that hydrogenotrophic methanogenesis was the dominant pathway for methane production. In the CAP, highest SMA was found in the centre of the pond, $\mathrm{C2}$, against both acetate and hydrogen, whilst in the SAP, the highest activity potential was found in chamber V1 against acetate and in chamber V4 against hydrogen (Table 1). Interestingly, SMA did not correlate with methane biogas production rates, which were found in the front chamber of both reactors. In C1 of the CAP headspace, biogas methane production 
was $2.92 \mathrm{LCH}_{4} \mathrm{~m}^{-3} \mathrm{WWT}$, or $87 \%$ of total methane biogas production, whilst production in $\mathrm{H} 1$ of the SAP was $4.19 \mathrm{LCH}_{4} \mathrm{~m}^{-3} \mathrm{WWT}$, or $83 \%$ of total SAP biogas methane production. Maximum biogas production measured in the second stage of the SAP was $2.23 \mathrm{LCH}_{4} \mathrm{~m}^{-3}$ WWT with a maximum biogas methane composition of $20 \%$ cf. 16.63 $\mathrm{LCH}_{4} \mathrm{~m}^{-3} \mathrm{WWT}$ and $71 \%$ for the first stage.

\subsection{Hydrodynamic studies and validation of CFD modelling}

Hydrodynamic performance of the systems was through a variety of established analytical tools. The theoretical HRT (HRTt, defined as pond volume divided by the flow rate), was compared with the actual HRT (HRTa), calculated from collected RTD data, to assess the overall hydrodynamic efficiency of the pond (Abbassi et al, 2009). Dead space volume was calculated using the method of Moreno (1990), to approximate the volume of the pond that is underutilised due to preferential flow patterns, and short circuiting quotients, S, were calculated with the method of Persson (2000), where a smaller $\mathrm{S}$ suggests greater short-circuiting. The RTD variance, $\sigma^{2}$, calculated from the method of Muttamara and Puetpaiboon (1997), the dimensionless dispersion number, $\delta$ (Abbassi et al, 2009), and the tanks in series model (Persson, 2000) were used to analyse the flow regime between completely mixed and plug flow conditions. Smaller $\sigma^{2}$ and $\delta$, and imply more plug flow conditions, whilst a larger number of tanks in series is also associated with plug flow.

Comparison of the CFD modelling outputs to results from the experimental tracer studies show that the CFD modelling produced consistently lower actual HRTs, shortcircuiting quotients, and variances, as well as consistently higher dead space volumes, 
dispersion numbers, and tanks in series calculation across all four of the pond configurations (Table 2). However, the CFD results gave comparatively similar results across the pond configurations as the experimental tracer studies. For example, both the CFD and tracer studies calculated the UAP have the highest dispersion number of the four configurations, followed by the HBAP, VBAP, and the SAP had the lowest. Therefore, whilst the CFD-generated results cannot be used as a direct relation to the pilot trials, the differences were consistent, and comparative analysis between reactor configurations is reflective of the pilot trials.

The most efficient hydrodynamic design of the four configurations studied was the SAP, with a dead space volume of $10 \%$ and a short-circuiting quotient, $S$, of 0.47 from the experimental RTD and dead space volume $=36 \%, S=0.36$ for the CFD simulation (Table 1). Short-circuiting quotients were similar in the baffled single stage ponds, whilst a higher degree of short-circuiting was evident in the unbaffled pond. Dead space volumes were also similar in the single-stage baffled ponds, but whilst these measures of overall pond hydrodynamics were similar, differences were evident in the flow regimes. The VBAP created more plug-flow conditions than the HBAP, with lower dispersion numbers and higher tanks in series (Table 2). The most plug-flow conditions were found in the SAP, with dispersion numbers $\delta_{\exp }=0.10,0.16,0.15$ and 0.26 , and $\delta_{C F D}=0.12,0.15,0.23,0.50$ for the SAP, VBAP, HBAP and UAP, respectively. The tanks in series models supported this finding, with the SAP and VBAP having similar $\mathrm{N}$ values, whilst the lowest values were found in the unbaffled pond. 
The velocity profiles generated in the CFD simulations provide further insight into the flow mechanisms generating the hydrodynamic data. In the UAP, where a high degree of short-circuiting was calculated, a clear preferential flow pattern can be observed passing from the inlet directly to the outlet (Figure 5). Recirculation, caused by the small area of the outlet compared to the flow rate, generates a back-mixing effect, although dead space was evident in the corners of the pond. In the baffled ponds, the preferential flow pattern was disrupted by the baffles, which generated their own back-mixing effect. Recirculation between baffles was evident, which reduced dead space by utilising more of the pond volume, whilst creating an overall plug-flow effect through the sequential detention of the flow in each chamber. This effect was more pronounced at higher velocities, as recirculation was evident in all three chambers of the horizontally baffled section of the SAP, whereas in the single stage HBAP, recirculation occurred in the front chamber but a preferential flow pattern was evident in subsequent chambers at the lower velocities.

\section{Discussion}

\subsection{Influence of baffle orientation on single staged ponds}

The removal efficiencies observed in the HBAP, compared to the VBAP, demonstrate that in single-stage systems baffle orientation can have a distinct effect on removal performance. The horizontal baffling, which extend the flow path length whilst detaining liquid flow through changes of horizontal direction, provide greater opportunity for settling of larger particles. In contrast, vertical baffling promotes 
mixing between the incoming flow and the settled solids. The consequence is a decreased solids removal but enhanced organics uptake when using vertical baffling as seen by a difference of $34 \%$ in the COD removal between the two baffling configurations. Accordingly, the two baffling configurations can be utilised to promote different functions within the pond so that treatment efficacy can be maximised. In the current case this was demonstrated by combining a HBAP and VBAP in sequence to encourage maximum solids capture in the first stage leading to increased carbon availability through hydrolysis that is then utilised in the second stage VBAP to maximum carbon degradation (Lettinga et al., 2001; Van Haandel et al., 2006).

\subsection{Performance of a staged anaerobic pond design}

Particulate removal in the SAP was close to the midpoint of the single stage reactors (pCOD removal $56 \%$ for the SAP cf. $78 \%$ for the HBAP and $32 \%$ for the VBAP), whilst negative soluble sCOD was still observed. Accordingly, positioning the HBAP upstream of the VBAP did provide particulate retention and, therefore, reduced biomass washout from the VBAP. However, the function of the VBAP fundamentally changed from operating as a primary stage to a secondary stage of treatment. Whilst soluble carbon degradation in the single stage VBAP is likely to have been driven by the biomass/substrate contact provided by both baffle orientation and the volume of biomass retained, particularly by the first baffle, the absence of such volumes of biomass in the second stage of the SAP may have reduced its effectiveness. With time, biomass build up in the second stage may improve soluble carbon degradation, or this process may be expedited with higher volumes of seed biomass in this second stage. 
Similarly baffled ABRs have previously been seeded with sludge volumes up to $80 \%$ (Barber and Stuckey, 1998; Langenhoff et al., 2000), and this may be required for more effective operation of the VBAP as the second stage.

In both the CAP and SAP, the first chamber, created between the inlet and first baffle, was found to be critical in the overall performance of the ponds. The vast majority of particulate removal, VFA generation, sludge accumulation and biogas production were found in this chamber in both ponds, irrespective that this chamber comprised a smaller proportion of the overall volume in the SAP than the CAP. Increased activity close to the inlet has been observed in unbaffled full-scale ponds (Schneiter et al., 1993; Paing et al., 2000; Picot et al., 2005), and can be attributed to the low flow rates applied to ponds leading to ineffective use of the entire pond volume.

The SMA assays found hydrogenotrophic methanogenesis to be dominant over acetoclastic pathways, which has been reported from other low-temperature anaerobic studies (Collins et al., 2005; Connaughton et al., 2006), congruent with the lack of acetate consumption in the ponds. The high SMA activity observed in the downstream chambers of the ponds demonstrates that the sludge, whilst lower in bulk volume than at the inlets, is still active (Paing et al., 2000). Previous investigations at full-scale have shown that APs can take up to two years to mature, especially with respect to VFA degradation (Paing et al., 2000; Picot et al., 2003). Further, acetoclastic methanogens, which have lower kinetic rates than hydrogenotrophic orders, and are more sensitive to lower temperatures (Connaughton et al., 2006), may establish in the ponds with extended operation time, especially in the second stage of the SAP where 
both the flow pattern and acetate-rich substrate would provide preferential conditions for growth. The construction and location of the pilot models resulted in liquid temperatures closer to ambient temperatures than to the influent, whilst at full-scale buffering caused by surrounding earthworks would lead to a higher and more stable temperature range within the pond (Safley Jr. and Westerman, 1989; Park and Craggs, 2007).

\subsection{Design development through CFD and pilot trials}

Both the CFD modelling and pilot trials have demonstrated value in improving anaerobic pond design, showing potential to be used to further enhance pond performance through the understanding of pond hydrodynamics, removal efficiency, and biogas production. The CFD simulations show how baffled AP designs reduce short-circuiting compared to the unbaffled case, by dissipating the inlet jetting effect (Persson, 2000; Shilton and Harrison, 2003; Agunwamba, 2006) and creating recirculation between baffles (Shilton, 2000). The lower dispersion numbers observed in the baffled systems, indicating plug-flow when increased mixing is expected, was explained through study of the velocity profiles generated. The recirculation effect in the baffled reactors, caused by backpressure at each baffle and seen in the velocity profiles, generates mixing within each chamber whilst creating an overall plug-flow effect of a series of stirred tanks (Grobicki and Stuckey, 1992). Recirculation was most pronounced in chamber 1 of both the HBAP and VBAP, with preferential flow patterns evident thereafter, suggesting baffle number may not have been a significant factor. Shilton and Harrison (2003) found that whilst a minimum of two baffles should be 
recommended, only small improvements are found with four baffles with further diminishing returns with increasing number of baffles. The ability of the CFD modelling to reflect the experimental tracer studies, if not precisely predict the true flows, show that CFD can be a useful tool in trialling a large number of potential designs without the time and expense of pilot trials, even though pilot trials should be conducted after the use of CFD as an initial selective tool (Abbas et al., 2006; Abbassi et al., 2009). Future advancements into multi-phase CFD models could incorporate solids transport and accumulation (Alvarado et al., 2012), biogas bubbling, and sludge and wastewater rheology, enabling modelling to more accurately reflect wastewater trials.

The pilot trials of both the single- and two-stage ponds also drew important findings that can further improve AP design. The concentration of removal and biogas production towards the front of the baffled ponds suggest higher loadings onto APs can lead to improved performance, with increased mixing leading to greater biomass/substrate contact that is essential for soluble carbon breakdown (Peña et al., 2003), whilst also reducing the physical footprint (Li, 1992; Agunwamba, 2001). Higher loadings rates applied to the designs in this study may lead to greater differences between the single and two-stage systems, through driving increased adaptation of the differing microbial communities developing along the ponds' length by providing increased organic strength and accentuating the current differences in flow patterns due to baffle design. In addition, the change in performance of the vertically baffled pond when placed in the two-stage system, opposed to its performance as a single-stage pond, suggest its function fundamentally changed. It is likely greater biomass volumes are required for seeding this downstream reactor, to ensure soluble COD can be effectively degraded. In 
addition, due to the long establishment times for anaerobic archaeal populations, extended operations of the systems would also likely lead to improved methanogenesis rates.

\section{Conclusions}

The influence of baffle configurations on the performance of APs was studied across a broad spectrum of performance indicators, with a two stage design developed to optimise the findings from single stage horizontal and vertical baffle trials.

- The influence of baffling on pond hydrodynamics was demonstrated through experimental tracer and CFD modelling. Whilst plug-flow tendencies were observed in the hydrodynamic data from baffled ponds, investigation of the CFD generated velocity profiles highlighted the recirculation within ponds, demonstrating the effectiveness of baffles in enhancing mixing whilst creating an overall plug-flow effect

- Differences in removal mechanisms were found between horizontally and vertically baffled single stage APs, with horizontal baffles found to promote sedimentation and solids removal at the expense of soluble carbon washout, whilst the reverse was true of the vertically baffled AP. This can be attributed to the horizontal flow regime promoted by the HBAP generating greater settlement of particulates, whilst the upflow sections of the VBAP carry particulates further through the pond whilst also enable enhanced substrate/biomass contact 
- A two stage AP design was developed, to promote sedimentation and solids breakdown in the first stage followed by targeting of the generated soluble fraction in the second stage. Whilst results at the low loading rates applied were not definitive, evidence suggests extended pond operation and higher loading rates may improve performance of the two stage AP

- Advantages of a two-stage system were found in improved hydrodynamic performance by optimising effective pond volume, higher and more stable biogas production compared to a single stage AP suggest more effective anaerobic breakdown, and evidence of the spatial distribution of the anaerobic digestion process which may lead to more efficient anaerobic digestion with time as different microbial communities establish in the different preferential conditions created

\section{Acknowledgements}

This work was supported by the Engineering \& Physical Sciences Research Council. Gavin Collins and Estefania Porca were supported by a European Research Council Starting Grant (3C-BIOTECH 261330)

\section{References}

Abbas, H., Nasr, R. and Seif, H. (2006), Study of waste stabilization pond geometry for the wastewater treatment efficiency, Water Environ. Res., 28(1), 25-34. 
Abbassi, R., Khan, F. and Hawboldt, K. (2009), "Characterization of parameters effect on hydraulic flow pattern of waste stabilization pond", Proc. Can. Soc. Civ. Eng. Vol. 1, 27-30th May, 2009, St. Johns, NL, Canada, CSCE, Montreal, Quebec, Canada, 463-472.

Agunwamba, J. C. (2006), Effect of the location of the inlet and outlet structures on short-circuiting: Experimental investigation, Water Environ. Res., 78(6), 580-589.

Agunwamba, J. C. (2001), Effect of tapering on the performance of waste stabilization ponds, Water Res., 35(5), 1191-1200.

Alexiou, G. E. and Mara, D. D. (2003), Anaerobic waste stabilization ponds: A low-cost contribution to a sustainable wastewater reuse cycle, Appl. Biochem. Microt, 109(1-3), 241-252.

Alvarado, A., Sanchez, E., Durazno, G., Vesvikar, M. and Nopens, I. (2012), CFD analysis of sludge accumulation and hydraulic performance of a waste stabilization pond, Water Sci. Technol., 66(11), 2370-2377.

APHA (1998), Standard Methods for the Examination of Water and Wastewater, 20th ed, American Public Health Association, Washington D.C., U.S.A.

Barber, W. P. and Stuckey, D. C. (1999), The use of the anaerobic baffled reactor (ABR) for wastewater treatment: A review, Water Res., 33(7), 1559-1578.

Barber, W. P. and Stuckey, D. C. (1998), The influence of start-up strategies on the performance of an anaerobic baffled reactor, Environ. Technol., 19(5), 489-501. 
Coates, J. D., Coughlan, M. F., and Colleran, E. (1996), Simple method for the measurement of the hydrogenotrophic methanogenic activity of anaerobic sludges. J. Microbiol. Methods 26, 237-246.

Colleran, E., Concannon, F., Golden, T., Geoghegan, F., Crumlish, B., Killilea, E., et al. (1992). Use of methanogenic activity tests to characterise anaerobic sludges, screen for anaerobic biodegradability and determine toxicity thresholds against individual anaerobic trophic groups and species. Water Sci. Technol. 25, 31-40.

Collins, G., Foy, C., McHugh, S., Mahony, T. and O'Flaherty, V. (2005), Anaerobic biological treatment of phenolic wastewater at $15-18^{\circ} \mathrm{C}$, Water Res., 39(8), 16141620.

Collins, G., Woods, A., McHugh, S., Carton, M. W. and O'Flaherty, V. (2003), Microbial community structure and methanogenic activity during start-up of psychrophilic anaerobic digesters treating synthetic industrial wastewaters, FEMS Microbiol. Ecol., 46(2), 159-170.

Connaughton, S., Collins, G. and O'Flaherty, V. (2006), Development of microbial community structure and actvity in a high-rate anaerobic bioreactor at $18^{\circ} \mathrm{C}$, Water Res., 40(5), 1009-1017.

Grobicki, A. and Stuckey, D. C. (1992), Hydrodynamic characteristics of the anaerobic baffled reactor, Water Res., 26(3), 371-378. 
Langenhoff, A. A. M., Intrachandra, N. and Stuckey, D. C. (2000), Treatment of dilute soluble and colloidal wastewater using an anaerobic baffled reactor: Influence of hydraulic retention time, Water Res., 34(4), 1307-1317.

Langenhoff, A. A. M. and Stuckey, D. C. (2000), Treatment of dilute wastewater using an anaerobic baffled reactor: Effect of low temperature, Water Res., 34(15), 38673875.

Lettinga, G., Rebac, S. and Zeeman, G. (2001), Challenge of psychrophilic anaerobic wastewater treatment, Trends Biotechnol., 19(9), 363-370.

Lew, B., Tarre, S., Beliavski, M. and Green, M. (2009), Anaerobic degradation pathway and kinetics of domestic wastewater at low temperatures, Bioresource Technol., 100(24), 6155-6162.

Li, X. W. (1992), Computer-aided design for stabilization ponds, Water Sci. Technol., 26(9-11), 2425-2428.

Mara, D. D. and Pearson, H. W. (1998), Design Manual for Waste Stabilization Ponds in Mediterranean Countries, 1st ed, Lagoon Technology International, Leeds: England.

McAdam, E. J., Ansari, I., Cruddas, P., Martin-Garcia, I., Lester, J. N., Pursell, N., Cartmell, E. and Jefferson, B. (2012), Waste stabilisation ponds for anaerobic wastewater treatment, P I Civil Eng.-Eng. Sus., 165(3), 201-213. 
Mshandete, A., Björnsson, L., Kivaisi, A. K., Rubindamayugi, S. T. and Mattiasson, B. (2005), Enhancement of anaerobic batch digestion of sisal pulp waste by mesophilic aerobic pre-treatment, Water Res., 39(8), 1569-1575.

Moreno, M. D. (1990), A tracer study of the hydraulics of facultative stabilization ponds, Water Res., 24(8), 1025-1030.

Muttamara, S. and Puetpaiboon, U. (1997), Roles of baffles in waste stabilization ponds, Water Sci. Technol., 35(8), 275-284.

Noyola, A., Morgan-Sagastume, J. M. and López-Hernández, J. E. (2006), Treatment of biogas produced in anaerobic reactors for domestic wastewater: Odor control and energy/resource recovery, Rev. Environ. Sci. Biotechnol., 5(1), 93-114.

Paing, J., Picot, B., Sambuco, J. P. and Rambaud, A. (2000), Sludge accumulation and methanogenic activity in an anaerobic lagoon, Water Sci. Technol., 42(10-11), 247255.

Park, J. and Craggs, R. J. (2007), Biogas production from anaerobic waste stabilisation ponds treating dairy and piggery wastewater in New Zealand, Water Sci. Technol., 55(11), 257-264.

Peña, M. R., Mara, D. D. and Piguet, J. M. (2003), Improvement of mixing patterns in pilot-scale anaerobic ponds treating domestic sewage, Water Sci. Technol., 48(2), $235-242$. 
Persson, J. (2000), The hydraulic performance of ponds of various layouts, Urban Water J., 2(3), 243-250.

Persson, J. and Wittgren, H. B. (2003), How hydrological and hydraulic conditions affect performance of ponds, Water Environ. Res., 21(4-5), 259-269.

Pescod, M. B. (1996), The role and limitations of anaerobic pond systems, Water Sci. Technol., 33(7), 11-21.

Picot, B., Andrianarison, T., Gosselin, J. P. and Brissaud, F. (2005), Twenty years' monitoring of Mèze stabilisation ponds: Part I - Removal of organic matter and nutrients, Water Sci. Technol., 51(12), 23-31.

Picot, B., Paing, J., Sambuco, J. P., Costa, R. H. R. and Rambaud, A. (2003), Biogas production, sludge accumulation and mass balance of carbon in anaerobic ponds, Water Sci. Technol., 48(2), 243-250.

Safley Jr., L. M. and Westerman, P. W. (1989), Anaerobic lagoon biogas recovery systems, Biol. Waste., 27(1), 43-62.

Salter, H. E., Ta, C. T., Ouki, S. K. and Williams, S. C. (2000), Three-dimensional computational fluid dynamic modelling of a facultative lagoon, Water Sci. Technol., 42(10-11), 335-342.

Schneiter, R. W., Middlebrooks, E. J., Sletten, R. S. and Reed, S. C. (1993), Sludges from cold regions lagoons, Water Environ. Res., 65(2), 146-155. 
Shilton, A. N. (2000), Potential application of computational fluid dynamics to pond design, Water Sci. Technol., 42(10-11), 327-334.

Shilton, A. N. and Harrison, J. (2003), Development of guidelines for improved hydraulic design of waste stabilisation ponds, Water Sci. Technol., 48(2), 173-180.

Shilton, A. N. and Mara, D. D. (2005), CFD (computational fluid dynamics) modelling of baffles for optimizing tropical waste stabilization pond systems, Water Sci. Technol., 51(12), 103-106.

Shilton, A. N., Mara, D. D., Craggs, R. J. and Powell, N. (2008), Solar-powered aeration and disinfection, anaerobic co-digestion, biological CO2 scrubbing and biofuel production: The energy and carbon management opportunities of waste stabilisation ponds, Water Sci. Technol., 58(1), 253-258.

Van Haandel, A., Kato, M. T., Cavalcanti, P. F. F. and Florencio, L. (2006), Anaerobic reactor design concepts for the treatment of domestic wastewater, Rev. Environ. Sci. Biotechnol., 5(1), 21-38.

Vega, G. P., Peña, M. R., Ramírez, C. and Mara, D. D. (2003), Application of CFD modelling to study the hydrodynamics of various anaerobic pond configurations, Water Sci. Technol., 48(2), 163-171.

Wood, M. G., Greenfield, P. F., Howes, T., Johns, M. R. and Keller, J. (1995), Computational fluid dynamic modelling of wastewater ponds to improve design, Water Sci. Technol., 31(12), 111-118. 

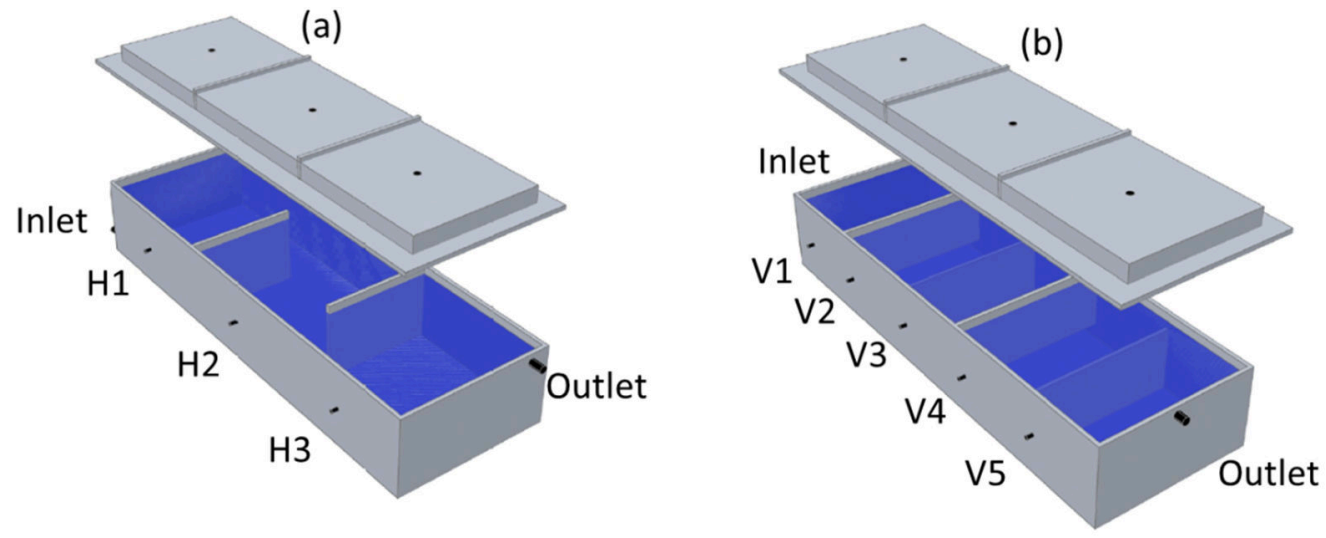

Figure 1 Layouts of the reactors used in the study. The (a) horizontally baffled anaerobic pond (HBAP) and (b) vertically baffled anaerobic pond (VBAP).

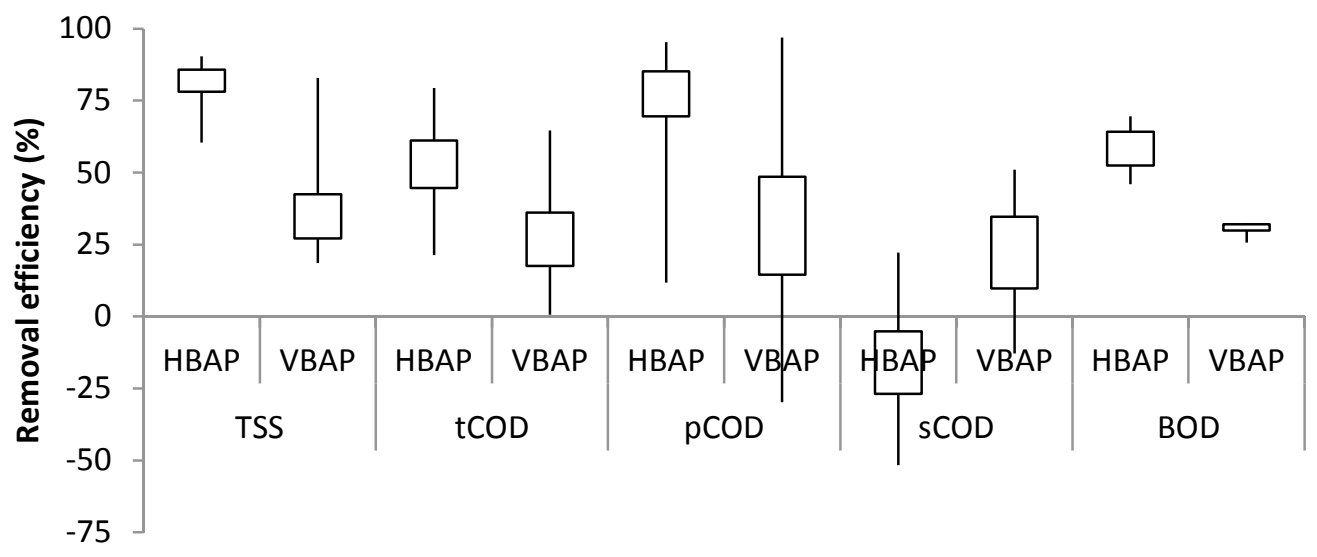

Figure 2 Removal efficiencies from the horizontally (HBAP) and vertically baffled (VBAP) anaerobic ponds. 


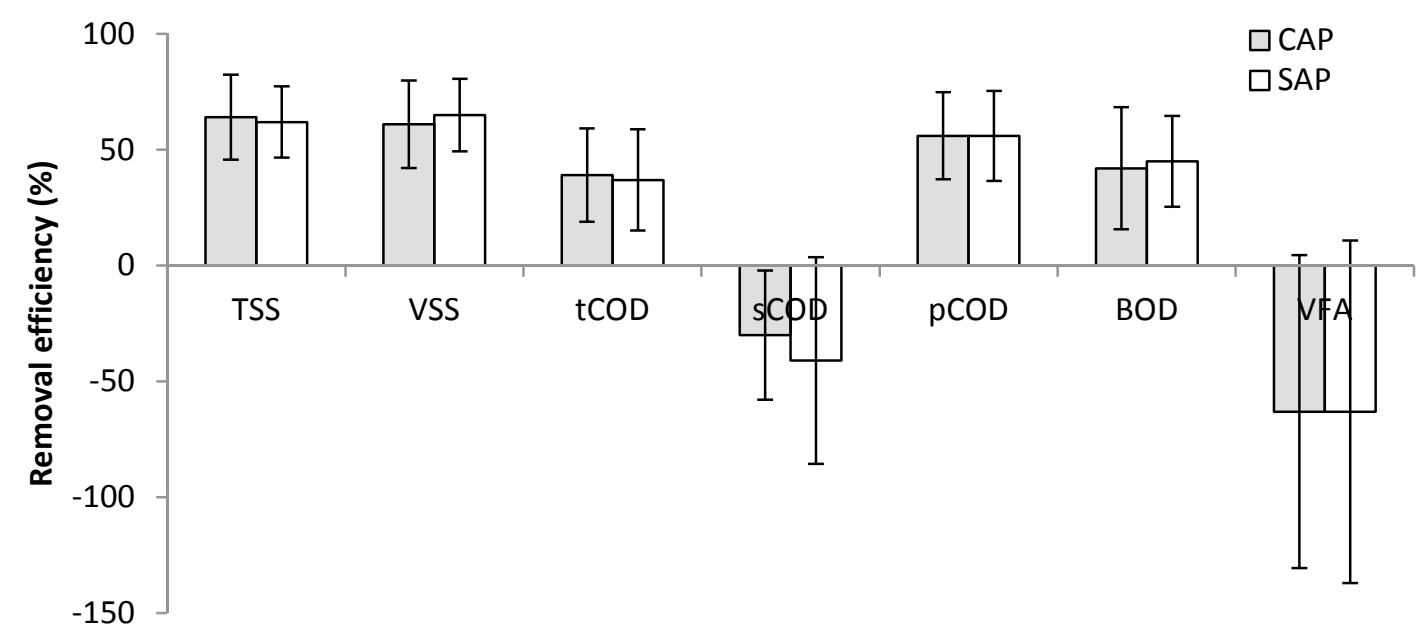

Figure 3 Removal efficiencies from the control (CAP) and staged (SAP) anaerobic pond trial. 
Table 1 Performance data from the staged anaerobic pond trial

\begin{tabular}{|c|c|c|c|c|c|c|c|c|c|c|c|c|c|c|c|c|c|}
\hline & \multirow{3}{*}{$\begin{array}{l}\text { Sampling } \\
\text { point }\end{array}$} & \multirow{3}{*}{$\begin{array}{l}\text { Length along } \\
\text { pond } \\
\text { L/Ltotal }\end{array}$} & \multirow[b]{3}{*}{$\mathrm{pH}$} & \multicolumn{9}{|c|}{ Concentration } & \multirow{3}{*}{$\begin{array}{c}\text { Acetic acid } \\
\text { proportion of } \\
\text { total VFA } \\
\%\end{array}$} & \multirow{3}{*}{$\begin{array}{c}\text { Vol acc. } \\
\text { sludge } \\
\text { L }\end{array}$} & \multirow{3}{*}{$\begin{array}{l}\text { Biogas methane } \\
\text { production } \\
\mathrm{LCH}_{4} \mathrm{~m}^{-3} \mathrm{WWT}\end{array}$} & \multirow{3}{*}{$\begin{array}{l}\text { Acetoclastic } \\
\text { SMA } \\
\mathrm{mgCH}_{4} \mathrm{gVSS}^{-1} \mathrm{~d}^{-1}\end{array}$} & \multirow{3}{*}{$\begin{array}{l}\text { Hydrogenotrophic } \\
\text { SMA } \\
\mathrm{mgCH}_{4} \mathrm{gVSS}^{-1} \mathrm{~d}^{-1}\end{array}$} \\
\hline & & & & TSS & VSS & tCOD & sCOD & $\mathrm{pCOD}$ & $\mathrm{BOD}_{5}$ & Alk & $\begin{array}{l}\text { Total } \\
\text { VFA }\end{array}$ & Acetic acid & & & & & \\
\hline & & & & \multicolumn{9}{|c|}{$\mathrm{mg} \mathrm{L}^{-1}$} & & & & & \\
\hline & Inf & N/A & 8.0 & 277 & 235 & 451 & 87 & 364 & 196 & 182 & 102 & 22 & 22 & N/A & N/A & N/A & N/A \\
\hline \multirow{4}{*}{ 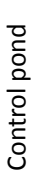 } & $\mathrm{C} 1$ & 0.17 & 7.22 & 151 & 132 & 309 & 151 & 158 & 177 & 195 & 154 & 74 & 48 & 15.0 & 2.92 & 0.61 & 13.94 \\
\hline & $\mathrm{C} 2$ & 0.50 & 7.18 & 148 & 128 & 312 & 136 & 176 & 115 & 209 & 171 & 91 & 53 & 5.6 & 0.26 & 1.77 & 956.95 \\
\hline & C3 & 0.83 & 7.18 & 117 & 98 & 279 & 131 & 149 & 106 & 217 & 148 & 78 & 53 & 3.1 & 0.19 & 0.73 & 841.03 \\
\hline & CAP eff & 1.00 & 7.60 & 80 & 76 & 239 & 109 & 130 & 93 & 200 & 134 & 64 & 48 & $23.7^{*}$ & $3.36^{*}$ & $1.04 * *$ & $604.03 * *$ \\
\hline \multirow{9}{*}{ 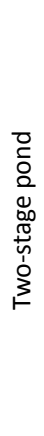 } & $\mathrm{H} 1$ & 0.13 & 7.34 & 612 & 535 & 1035 & 85 & 950 & 252 & 384 & 126 & 59 & 47 & 20.6 & 4.19 & 8.79 & 359.66 \\
\hline & $\mathrm{H} 2$ & 0.25 & 7.28 & 119 & 104 & 261 & 97 & 164 & 72 & 401 & 139 & 63 & 45 & 7.9 & 0.15 & N/A & N/A \\
\hline & H3 & 0.38 & 7.37 & 97 & 88 & 259 & 78 & 181 & 66 & 408 & 116 & 51 & 44 & 5.9 & 0.04 & 11.52 & 54.32 \\
\hline & V1 & 0.55 & 7.59 & 99 & 86 & 221 & 70 & 151 & 63 & 387 & 79 & 27 & 34 & 4.1 & 0.28 & 16.17 & $2,829.37$ \\
\hline & V2 & 0.65 & 7.40 & 71 & 62 & 214 & 101 & 113 & 66 & 428 & 106 & 57 & 54 & 3.5 & N/A & 0.24 & 532.50 \\
\hline & V3 & 0.75 & 7.56 & 70 & 57 & 220 & 89 & 132 & 66 & 395 & 95 & 33 & 35 & 3.9 & 0.33 & 7.06 & 936.31 \\
\hline & V4 & 0.85 & 7.47 & 86 & 75 & 242 & 107 & 135 & 61 & 442 & 121 & 65 & 54 & 3.3 & N/A & 0.02 & $4,144.58$ \\
\hline & V5 & 0.95 & 7.53 & 77 & 71 & 210 & 86 & 124 & 57 & 421 & 97 & 46 & 47 & 4.0 & 0.04 & 0.14 & $1,369.48$ \\
\hline & SAP eff & 1.00 & 7.60 & 91 & 72 & 245 & 114 & 132 & 91 & 208 & 136 & 64 & 47 & $53.1^{*}$ & $5.03 *$ & $6.28 * *$ & $1,460.49 * *$ \\
\hline
\end{tabular}

TSS - total suspended solids, VSS - volatile suspended solids, tCOD - total chemical oxygen demand, SCOD - soluble chemical oxygen demand (<1.2 $\mu \mathrm{m})$, pCOD - particulate chemical oxygen demand (>1.2 $\mu \mathrm{m}), \mathrm{BOD}_{5}-5$ day biochemical oxygen demand, Alk - alkalinity, VFA - volatile fatty acid, Vol acc. sludge - total accumulated sludge volume for chamber, SMA - specific methanogenic activity

$*$ total for entire pond, ${ }^{* *}$ weighted mean average for entire pond 


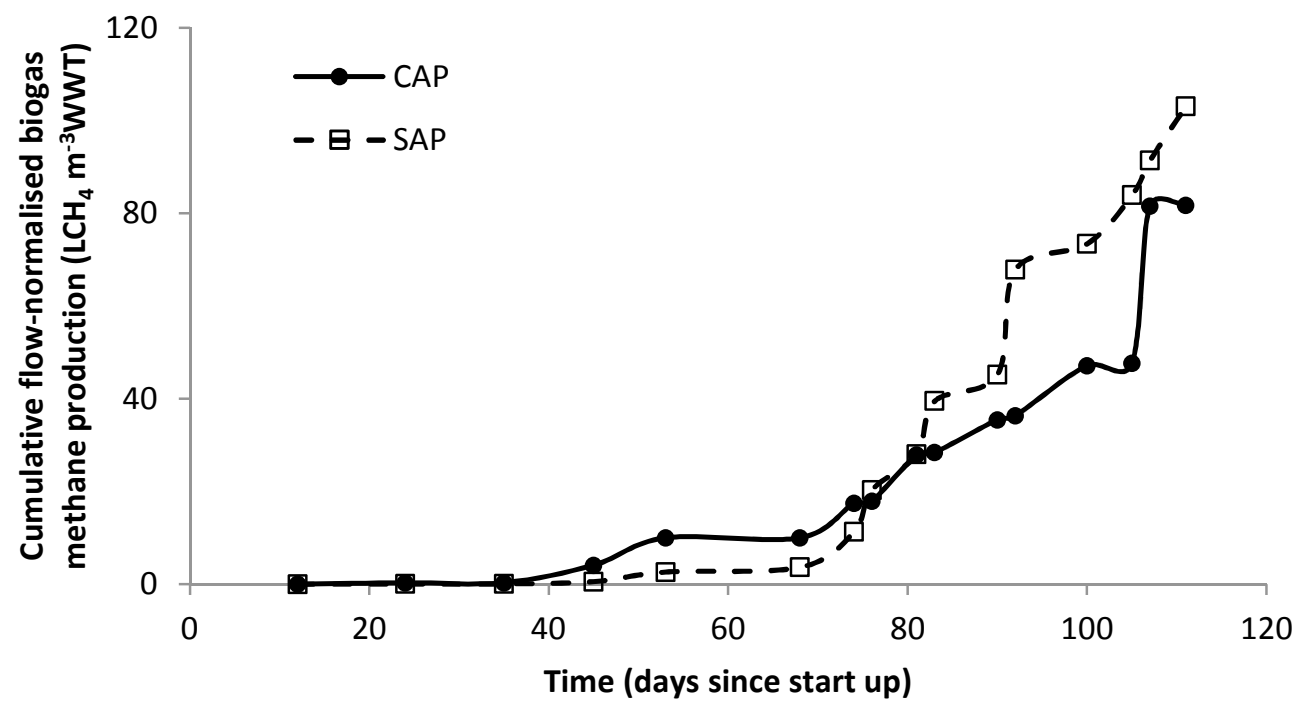

Figure 4 Cumulative flow-normalised biogas methane production in the control (CAP) andstaged (SAP) anaerobic ponds. 
Table 2 Hydrodynamic data calculated for four anaerobic pond designs with experimental tracer studies and computational fluid dynamics modelling

\begin{tabular}{|c|c|c|c|c|c|c|c|c|c|c|c|c|c|c|}
\hline & \multicolumn{3}{|c|}{ UAP } & \multicolumn{3}{|c|}{ VBAP } & \multicolumn{3}{|c|}{ HBAP } & \multicolumn{3}{|c|}{ SAP } & \multicolumn{2}{|c|}{ Difference } \\
\hline & Exp. & CFD & Diff & Exp. & CFD & Diff & Exp. & CFD & Diff & Exp. & CFD & Diff & $\mu_{\text {diff }}$ & $\sigma$ \\
\hline $\mathrm{HRT}_{\mathrm{a}}$ (d) & 1.75 & 1.38 & 0.37 & 1.69 & 1.33 & 0.36 & 1.85 & 1.33 & 0.52 & 2.07 & 1.48 & 0.59 & 0.46 & 0.10 \\
\hline $\mathrm{HRT}_{\mathrm{a}} / \mathrm{HRT}_{\mathrm{t}}(\%)$ & 76 & 60 & 16 & 73 & 57 & 16 & 80 & 57 & 23 & 90 & 64 & 26 & 20 & 4 \\
\hline Short-circuiting quotient, $\mathrm{S}$ & 0.22 & 0.18 & 0.04 & 0.43 & 0.32 & 0.11 & 0.40 & 0.29 & 0.11 & 0.47 & 0.36 & 0.11 & 0.09 & 0.03 \\
\hline Dead space volume (\%) & 24 & 40 & -16 & 27 & 43 & -16 & 20 & 43 & -23 & 10 & 36 & -26 & -20 & 4 \\
\hline Variance, $\sigma^{2}$ (days $\left.{ }^{2}\right)$ & 1.20 & 1.08 & 0.12 & 0.72 & 0.45 & 0.27 & 0.90 & 0.62 & 0.28 & 0.76 & 0.47 & 0.29 & 0.24 & 0.07 \\
\hline Dispersion number, $\delta$ & 0.26 & 0.50 & -0.24 & 0.15 & 0.15 & 0 & 0.16 & 0.23 & -0.07 & 0.10 & 0.12 & 0.01 & -0.07 & 0.10 \\
\hline Tanks in series, $\mathrm{N}$ & 4.49 & 4.95 & -0.46 & 7.43 & 11.93 & -4.50 & 5.96 & 8.61 & -2.65 & 7.06 & 11.43 & -4.37 & -3.00 & 1.64 \\
\hline Tracer recovered (\%) & 102 & 68 & 34 & 94 & 94 & 0 & 100 & 91 & 9 & 110 & 94 & 16 & 15 & 12 \\
\hline Maximum velocity $v_{\max }\left(\mathrm{m} \mathrm{s}^{-1}\right)$ & N/A & $1.47 \times 10^{-2}$ & N/A & N/A & $1.37 \times 10^{-2}$ & N/A & N/A & $1.52 \times 10^{-2}$ & N/A & N/A & $1.04 \times 10^{-1}$ & N/A & N/A & $\mathrm{N} / \mathrm{A}$ \\
\hline Minimum velocity $V_{\min }\left(\mathrm{m} \mathrm{s}^{-1}\right)$ & N/A & $1.21 \times 10^{-9}$ & N/A & N/A & $7.10 \times 10^{-11}$ & N/A & N/A & $1.83 \times 10^{-9}$ & N/A & N/A & $7.22 \times 10^{-8}$ & N/A & N/A & N/A \\
\hline
\end{tabular}

UAP - Unbaffled anaerobic pond; VBAP - vertically baffled anaerobic pond; HBAP - horizontally baffled anaerobic pond; SAP = staged anaerobic pond; Exp. experimental tracer study data; CFD - computational fluid dynamics simulation data; Diff = difference between experimental and CFD values; $\mu_{\text {diff }}-$ mean difference between experimental and CFD for all cases; $\sigma$-standard deviation of $\mu_{\text {diff }}$ 

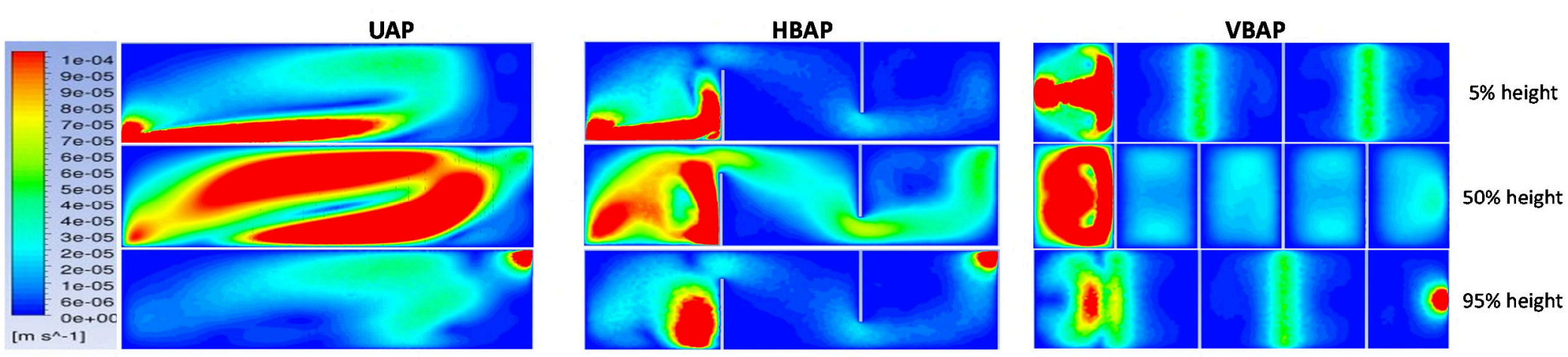

SAP

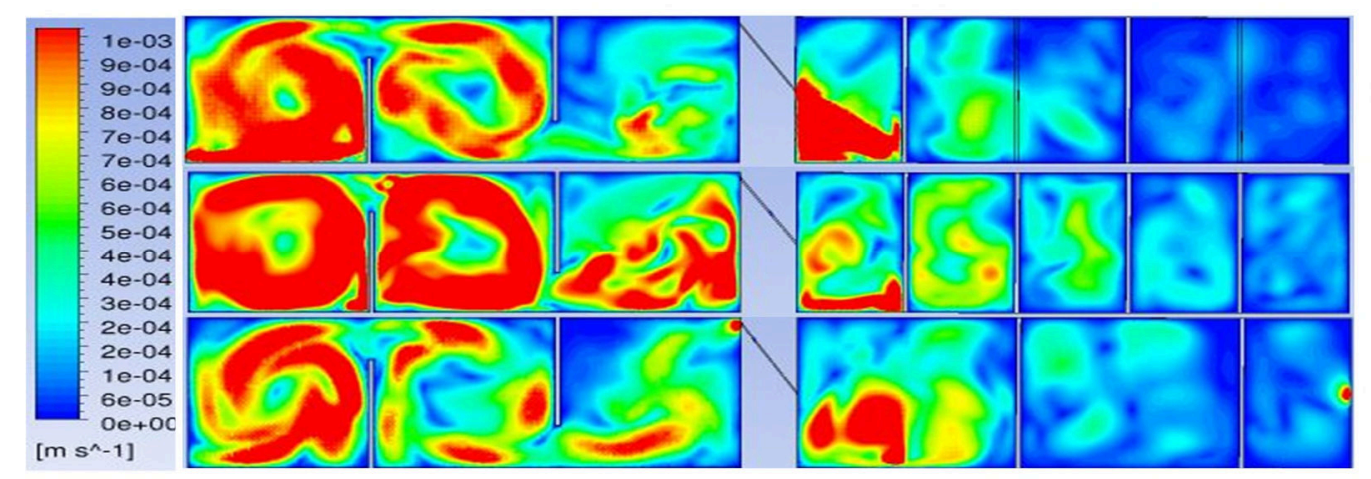

$5 \%$ height

$50 \%$ height

$95 \%$ height

Figure 5 Velocity profiles generated from computational fluid dynamics for the unbaffled (UAP), horizontally baffled (HBAP), vertically baffled (VBAP) and the staged anaerobic ponds (SAP) 